\title{
La dimensión espiritual en Terapia Ocupacional
}

Marta Lucía Santacruz G.*

Este artículo surgió a partir de búsquedas alrededor de las llamadas terapias alternativas y su posible aplicación dentro de la terapia ocupacional como respuesta a las necesidades del hombre contemporáneo y a constantes encuentros sobre está temática en la revista Canadiense de Terapia Ocupacional, desde comienzos de los años noventa, donde la dimensión espiritual del hombre y la ocupación, es incluida dentro de los cuatro componentes del desempeño ocupacional, concepto trabajado desde la Asociación Canadiense de Terapia ocupacional (CAOT, 91), que ha tratado de definirlo y estructurarlo dentro del modelo del desempeño ocupacional, con referentes teóricos que parten de las teorías humanistas y del modelo de la terapia centrada en el cliente, o la persona, (Rogers, 1951), el cual se puede decir es hijo de las corrientes humanistas y existencialistas, tendencias acordes con los principios filosóficos de la profesión que determinan la visión holística del hombre, quien se considera tiene motivación intrínseca para la acción y derecho a una existencia con propósito y significativa.

El concepto de la espiritualidad ha tomado un importante lugar en el modelo de práctica desarrollado por la Canadian Association of Occupational therapys, (CAOT, 1991 ) ; en 1992 Blain, Towsend, Krefting \& Burwash presentaron una definición de la espiritualidad pertinente al desempeño ocupacional y la practica del terapeuta ocupacional, allí sugieren que la espiritualidad de la persona es su verdadera esencia y que esta se conecta con todas las cosas y experiencias de su vida. Afirman que para mantener el bienestar espiritual el individuo debe permanecer en conexión con el sí mismo, con los otros y con el resto de la creación, como también permitirse expresar su verdadera naturaleza.

* Terapeuta Ocupacional. Especialista en docencia universitaria. Docente Escuela colombiana de Rehabilitación. 
La espiritualidad es vista como uno de los cuatro componentes de ejecución dentro del modelo del desempeño ocupacional (CAOT, 91), y ha sido definido como "una visión del yo en el futuro", entendido el individuo como un todo, un ser holístico compuesto por la interacción compleja de factores que incluyen componentes físicos, mentales, socioculturales y espirituales; para determinar la existencia de éste componente dentro de la persona, se requiere explorar el significado que le da a las experiencias diarias y las actividades que le ofrecen significado a su sí mismo y a su vida, aspectos que vistos desde la perspectiva de Terapia ocupacional son centrales en los procesos de recuperación, siendo la espiritualidad la representación de la persona como un todo dentro de su contexto.

Como se mencionó arriba, el concepto de la espiritualidad también se ha trabajado dentro del modelo práctico de la atención centrada en el cliente, (CAOT, 91), donde se ve la espiritualidad como un componente esencial del individuo quien está en una interacción dinámica entre mente y cuerpo, es la que da la visión del propósito de vida en cada persona y se considera que dicha expresión se va configurando a través de los procesos de socialización de los sistemas de creencias y de valores.

En el modelo de la practica centrada en el cliente, la inclusión de lo espiritual admite la visión positivista del hombre, dándole importancia al sentido del yo de la persona, sus creencias sobre su poder y control y el significado que le da a la vida, componentes que se adquieren por la interacción con el ambiente y se estructuran internamente. Esta dimensión espiritual del individuo no es simplemente un componente de su ser, sino que implica al sí mismo, pues cada persona es un ser y es espíritu, que lo hace parte integral del universo y existe y permanece como un todo a pesar de una enfermedad o lesión. Se cree que cada individuo tiene un mundo intrínseco que lo motiva a la acción, que lo expresa a través de su participación en actividades diarias, aspectos que desde la perspectiva de terapia ocupacional se agrupan en las áreas de esparcimiento, autocuidado y trabajo.

Dimensión espiritual que se puede integrar tanto en estados de salud como de enfermedad, también ante una crisis espiritual donde la persona entra en el cuestionamiento de sus creencias, valores y propósitos, crisis que se puede ligar a los cambios implícitos en los procesos de rehabilitación.

En 1995 la AOTA, presento una definición sobre la dimensión espiritual de la ocupación, la definió como los aspectos no físicos y no materiales de la existencia, que 
contribuye con el conocimiento profundo de la naturaleza y significado de la vida de la persona.

Tenemos entonces que la espiritualidad es un fenómeno metafísico, de difícil definición, donde su naturaleza se acoge a la quinta esencia o el quinto elemento más allá del agua, del fuego, la tierra y el aire, inmersos en los pensamientos y en las cosas.

Egan A de Laat en 1994, presentó la espiritualidad humana como la esencia de una persona expresada en sus acciones diarias e influida por sus valores, su sistema de creencias y su contexto sociocultural. Todos somos espirituales, esto no está confinado a la religión o la teología, el espíritu ha sido llamado aliento de vida, aliento de inspiración y puede ser el impulso o bien la motivación para descubrir el significado y propósito de la vida.

En Hebreo, Latín y otros lenguajes asiáticos la palabra espiritual significa literalmente aliento o aire en movimiento, Perry (1986), menciona que en la antiguedad se consideraba al espíritu como el impulsor de la vida, como la fuerza de motivación humana.

Por otra parte la filosofía griega, la hindú y la tradición budista ven la espiritualidad como la esencia del individuo el cual reside en el cuerpo, Pagels, (1979). Jung en el 57 , la definió como la principal guía dentro de la vida psíquica que regula los pensamientos, llevando a una autoconciencia significativa y a un sentido de bienestar.

Bellingham, Cohen, Jones, and LeRoy en 1989, definen la espiritualidad como la habilidad par vivir de manera integra, propósito que requiere de la conexión de tres esferas:

1. La primera es la conexión con el sí mismo, que se logra por la permanente conciencia de nuestros propios sentimientos, cuando esto se pierde resulta la pérdida de la autodirección.

2. La segunda esfera se refiere a nuestras relaciones con los otros, la falla èn esto resulta en soledad y aislamiento.

3. La tercera se conecta con el resto de la creación, incluyendo el creador, en esta esfera se encuentra el significado y propósito de vida de cada persona, la falla en esta resulta en la alienación de los principios que guían la existencia y se genera un profundo sentimiento de aburrimiento, vacío y temor. 
Por su parte en 1991 Muldon y king, ampliaron el concepto de espiritualidad a la expresión del ser propio, refiriendo que la espiritualidad de la persona es la forma como maneja su vida; en este sentido cada ser humano es espiritual, en la dirección que le da a la vida, en la historia de vida que cada uno relata se encuentran las raíces y envuelve la forma de ver la vida. Esta visión se apoya en actividades individuales o grupales o bien prácticas organizadas sustentadas y expresadas, como son las diversas formas de reflexión, oración, conversación, de participación en rituales sociales y la asimilación de actitudes dadas por comunidad.

Hasta el momento se ha dificultado la aplicación de la dimensión espiritual a la practica diaria del terapeuta ocupacional, débido en parte por las limitaciones para definirla ya que es un concepto abstracto y resulta difícil operacionalizarla dentro del desempeño del terapeuta, ya que no es un comportamiento observable que se pueda medir, además existe la tendencia a confundir el término con elementos religiosos que no deben ser incluidos dentro de la relación terapéutica (esta diferencia ya se explico anteriormente), también está el desconocimiento en general sobre lo que este concepto trabaja y sobre cómo puede ser involucrado en el proceso de intervención a través de nuevas estrategias que las actuales corrientes terapéuticas que se sustentan en principios espirituales aportan y que a mi manera de ver abordan aspectos internos del sujeto que determinan su compromiso con el tratamiento y la superación de la crisis de vida que la discapacidad por si misma genera.

En relación con lo anterior retomo a Peloquin (95), en sus planteamientos acerca de lo que es ser terapeuta ocupacional, donde la considera como el artista en las personas, que al ofrecer la experiencia a través de la ocupación potencializa en el sujeto su capacidad para descubrir el significado y el propósito de su vida. Afirma que la práctica se convierte en arte cuando la capacidad empática del terapeuta logra transformar la experiencia del cliente desde una alienación hacia el autoentendimiento, la autorenovación y la trascendencia. En este sentido es a través de actividades estructuradas externamente que el terapeuta ocupacional crea, mantiene, altera y modifica el contexto del tratamiento para transformar la parte interna del cliente y sus experiencias de desorden y disfunción dentro de un orden significativo y con propósito.

Es así como a través del arte de la práctica se potencializan en el individuo relaciones significativas con el sí mismo y el mundo, lo que actúa como medio transformador mediante el que reconoce y aprende a aceptar sus propias fuerzas, sus limita- 
ciones, a apreciarse como ser humano con identidad y descubrir el significado de su existencia (Mosey 86).

Dentro del modelo de desempeño ocupacional (CAOT, 91), La espiritualidad ha estado ligada al significado de vida y a varios aspectos de la misma, lo que implica la reflexión filosófica de cómo la persona alcanza un conocimiento consciente del significado de su vida a través de su participación en actividades diarias, de cómo la significación que le de a los eventos diarios va a determinar en ella una existencia con propósito y trascendencia y sobre cómo es el hacer y la experiencia los participantes directos de está dimensión.

Es hacernos conscientes de que somos profesionales quienes desde una formación humanista abordamos al usuario como un todo inmerso en un contexto que le demanda participación y pertenencia a través del desempeño de ocupaciones, que al tornarse en experiencias convierten el componente espiritual en un fenómeno que se da en el aquí y ahora.

Además, si la meta del terapeuta ocupacional se dirige básicamente al bienestar de la persona y a una mejor calidad de vida, el ir más allá de un logro funcional está dado por la dimensión espiritual implícita en los niveles de logro y satisfacción personal, que a su vez deben desencadenar nuevas búsquedas, es así como el mismo hacer es el generador de la dinámica ocupación-propósito-bienestar, inmersos en una existencia significativa bien sea en estados de función o disfunción. El significado se va creando día a día y aquí el rol del terapeuta ocupacional está en ayudar al cliente a crear y afirmar su existencia (Peloquin, 95).

Las actividades que se sustentan en principios relacionados con la dimensión espiritual de la ocupación, deben crear la oportunidad para construir significados, lo que es necesario para establecer una identidad, ganar sentido de control y conectarse con la historial personal, favoreciendo el logro de competencias para manejar el estrés y las adversidades de la vida diaria de manera que se obtenga bienestar (Peloquin, 95).

Brenda Howar y Jay R. Howard en el 96, sustentan la ocupación como una actividad espiritual, afirmando que la ocupación es la base del bienestar, que ofrece significado a la vida y que a su vez la espiritualidad permea todas las áreas de la ocupación, de ahí la cadena entre estas. Refieren que los procesos terapéuticos 
pueden ser vistos como " jornadas de reconciliación y transformación espiritual ", ya que el significante asociado a la ocupación ofrece una dimensión espiritual.

Belligham Et. col en 1989, describieron una manera para establecer y mantener la dimensión espiritual, trabajando la conexión de las tres esferas espirituales, descritas anteriormente, y a partir de las cuales se pretende ligar estrategias desde la perspectiva de terapia ocupacional de manera que se logren aspectos de autonomía personal social en el cliente:

1. Primera esfera, para conectarse con el sí mismo, se requiere de momentos de quietud y soledad, el individuo es guiado a explorar sus sentimientos, reconociendo y aceptando sus emociones y examinando cómo estas influyen sus acciones, se lo lleva a que explore sus valores y creencias y que se conecte consigo mismo actuando en congruencia con estos.

Aquí el terapeuta ofrece experiencias de acción que posibiliten en el individuo cambiar sus pensamientos de incapacidad a capacidad a través del logro y el éxito en la actividad, de manera que se influya en sus sistemas de valores y creencias al encontrarse consigo mismo en acciones con propósito.

Mediante técnicas psicoeducativas el individuo logra tomar autoconciencia y adquiere herramientas para manejar el estrés y síntomas de su enfermedad que alteren su desempeño ocupacional, educándolo sobre técnicas de relajación, meditación, visualización, imaginación y autodirección.

Mediante experiencias artísticas y creativas el terapeuta acompaña al usuario al encuentro con el sí mismo, al descubrimiento de nuevos valores y de nuevas relaciones con el mundo de los objetos, encontrando así nuevos símbolos y significados a su existencia.

2. Dentro de la segunda esfera, para trabajar la conexión con los otros se lleva a que la persona evalúe sus relaciones físicas, emocionales e intelectuales con los otros, participando con su propio yo en el establecimiento de conexiones compartiendo espacio, tiempo y sentimientos con otros.

Lo anterior se dimensiona dentro de experiencias grupales donde se promueva el encuentro con el sí mismo a través del encuentro con el otro, donde el dar 
y recibir esté implícito en la estructura y organización de la actividad bien sea a nivel corporal, mental o emocional.

Deben ser espacios de comunicación y expresión a través del silencio y la palabra manejados desde la capacidad empática del terapeuta.

Son importantes los grupos de apoyo y la participación de la familia déntro de los procesos de rehabilitación y de reconstrucción de la realidad del sujeto.

3. La tercera esfera se construye llevando al sujeto a que encuentre o bien reencuentre un significado a su existencia y un propósito a su vida, que sea congruente con sus sentimientos, valores y creencias, descubriendo la importancia de una vida creativa.

Fox en 1990, habló de ser cocreadores con el creador, de nuestra propia existencia y del universo, a través de la poesía, la prosa, la música, el arte, el deporte, en el mismo acto de cocinar, en las rutinas diarias y en la forma de gratificarse con la acción.

El terapeuta ocupacional debe diseñar experiencias de acción que partan de los intereses, necesidades y del sistema de creencias y valores del cliente, teniendo presente que a pesar de la discapacidad existente la persona es consciente de su deber y derecho a tener una vida con propósito y significado, o bien de resignificar su dimensión espiritual.

Pero, ¿̇cómo convertir la actividad terapéutica en una experiencia de crecimiento espiritual?, aspecto dado en parte por la misma calidad de vida y significaciones internas que posea el terapeuta, por un componente espiritual que además de existir dentro de sí sea congruente con su sí mismo, por acciones que involucren al otro o bien al propio usuario como ser en transformación y por su capacidad de llevar una existencia creativa, de lo contrario actuará como terapeuta desligada de su condición humana, negándose posibilidades de aprendizaje y crecimiento.

El terapeuta ocupacional debe entender la espiritualidad del cliente (Urbanowski, Vargo, 94), para obtener logros en la intervención, entrar en su realidad, siendo esto el fundamento para establecer una relación de ayuda construida sobre la confianza, la apertura y la empatía, esto significa entender a la persona desde su perspectiva ( Purtilo, 90). 
Por su parte Miller en 1990, describe la experiencia de transformación de individuos con enfermedades psiquiátricas crónicas, lo que refirió como crisis espiritual y la describió tomando a Oates,78. así:

Estado en el que la persona esta agudamente enferma y con gran significación e interpretación de caos a su existencia. Estos individuos se trabajan tratando de que resuelvan tales problemas liberando viejos patrones de vida y descubriendo nuevos patrones de existencia, sugiere la forma de llevar al individuo a través de estos procesos dentro de su rehabilitación:

- Normalizar la crisis.

- Afirmar las fortalezas individuales.

- Reconocimiento por parte del individuo de experiencias subjetivas.

- Balance de esas experiencias con su realidad externa.

- Comunicación de esperanza y aceptación.

Por medio de:

- Una relación de escucha, de confianza y honestidad mutua.

- Describirle y que identifique experiencias transpersonales.

- Recomendarle material de lectura.

- Facilitarle la autoconciencia a través de la afirmación, el contacto visual, la idenficación de sus bondades y apoyando su expresión creativa.

Es importante que el terapeuta entienda la espiritualidad de la persona y qué y quienes de su ambiente le son importantes, establecer la forma como vive el sujeto su discapacidad, lesión o crisis y para esto debe:

1. Identificar el significado de futuro para el cliente a la luz de su experiencia diaria, elaborando preguntas como: ¿cómo podría ser diferente su vida?, ¿cómo se ve a sí mismo para cuando vuelva a su casa?, si pudiera cambiar algo sobre sí mismo, excepto su actual situación, ¿qué cambio haría?

2. Identificar el significado que le da a actividades futuras que pueda realizar con otras personas con base en experiencias corrientes, preguntándole por ejemplo ¿quién es la persona más importante en su vida?, ¿cómo podrá variar su vida mediante diferentes actividades?

3. Identificar la importancia que le da a participar en actividades diarias, preguntándole sobre ¿cuáles son las tres cosas más importantes que es capaz de 
realizar en su casa?, ¿cuáles cosas quisiera volver a hacer en la forma como las hacía?

Para un proceso de rehabilitación con logros es importante que el usuario esté en posibilidad de establecer metas de acuerdo a su escala de valores y que le ofrezcan significados reales desde su propia perspectiva, así su espiritualidad está siendo considerada en el servicio que se le ofrece. Esto implica la habilidad del terapeuta para interpretar la importancia de las actividades en concordancia con la realidad del cliente y consistentes con sus metas personales. Para Reed y Sanderson, 1992, la meta del terapeuta debe centrarse en la salud y el bienestar de la persona dentro de su ambiente, esto incluye su espiritualidad y las metas para cada cliente, así, la terapeuta se convierte en parte integral del mundo del individuo y lo acompaña en la reconstrucción de su propia realidad, pero también es importante que al diseñar el proceso de rehabilitación no lo haga desde sus propios valores y necesidades, sino desde una clara comprensión del mundo interno del cliente.

\section{BIBLIOGRAFÍA}

Collins, M. Occupational therapy and spirituality: reflecting on quality of experience in therapeutic interventions. Brithish journal of Occupational therapy. 61(6). 1988.

Egan, M.; Delaat, M. The Implicit spirituality of occupational therapy practice. Canadian journal of Occupational therapy. 64(3). 1997.

Egan, M.; Delaat, M. Considering spirituality in occupational therapy practice. Canadian journal of Occupational therapy. 61(2). 1994.

Hume, C. Spirituality: a part of total care? British journal of Occupational therapy. 62(8). 1999.

Rose, A. Spirituality and palliative care: the attitudes of occupational therapistis. British journal of Occupational therapy. 62(7). 1999.

Unruh, A. Spirituality and occupation: Garden Misings and the Himalayan blue poppy. Canadian journal of Occupational Therapy. 64(3). 1997.

Urbanowski R.; Vargo, J. Spirituality, daily practice, and the occupational performance model. Canadian journal of Occupational Therapy. 61(2). 1994. 